\title{
TSUNAMI MODELLING AND RISK MAPPING FOR EAST COAST OF SABAH, MALAYSIA
}

\author{
Dr. Claus Pedersen ${ }^{1}$, Ir. Ziauddin Abdul Latif ${ }^{2}$, Caroline Lai',
}

\begin{abstract}
A tsunami risk mapping study for the east coast of the state of Sabah, Malaysia, has been initiated by the Government of Malaysia. The main objective is to produce tsunami risk maps that can be taken into account in local planning for the coastal zone. The study covers a coastline of more than a thousand kilometers which generally is sparsely populated outside the main population centers. The study is regional in character, but with additional focus on the main population centers. The paper outlines the overall steps of hazard mapping through source identification and modelling followed by tsunami wave propagation and potential modelling of overland flow. Modelling challenges related to sparse bathymetry data, limitations to resolution due to the large coverage required combined with a complex bathymetry with coral reefs, islands and outcrops is discussed. Data and model resolution for overland flow modelling is discussed. For the present study, it was found that the inaccuracies in the topographic data is of similar magnitude to the expected inundation levels, and caution has to be exercised in deriving hazard levels from the overland flow modelling. For a regional scale risk mapping exercise, and in the absence of very detailed topographic data, it may be preferable to use the wave height along the coastline as a hazard indicator rather than potentially inaccurate inundation levels and overland flow velocities.
\end{abstract}

Keywords: Tsunami modelling, tsunami hazard assessment and risk mapping.

\section{INTRODUCTION}

The 2004 Indian Ocean Tsunami, which killed an estimated quarter million people in 14 countries surrounding the Indian Ocean, was a stark reminder of the risks associated with tsunamis along exposed coastlines. With an average of about one every three years, tsunamis are more common in the Indian Ocean than realises by most, but far less common than in the Pacific Ocean, which registers about 8 tsunamis per year, see e.g. Rastogi and Jaiswal, 2006. Most of the tsunamis are limited in magnitude and restricted to local scale damage, and although the consequences can be of catastrophic proportions locally, they do generally not remain headline news for long or lead to national or international initiatives or policy changes. In contrast, the 2004 Indian Ocean Tsunami, generated by a Magnitude 9.2-9.3 earthquake off the northwest coast of Sumatra, was on a scale that impacted the livelihood of millions of people in several countries, leading to a global awareness shift in both the general population, within the scientific community and at the level of policy makers in many countries surrounding the Indian Ocean.

Contrary to the Pacific Ocean, which has regional and international tsunami warning centres in place, the emergency preparedness for the Indian Ocean rim countries prior to the 2004 Indian Ocean Tsunami was largely non-existent. Following the 2004 event, a number of national and international initiatives, ranging from mangrove replanting to tsunami detection, warning and evacuation systems, have been undertaken at different levels to manage and mitigate the risks associated with tsunami.

In Malaysia, one such initiative is a tsunami modelling and risk mapping exercise for the East Coast of Sabah, undertaken by the Ministry of Natural Resources and Environment through the Department of Irrigation and Drainage. The East Coast of Sabah does not face the Indian Ocean, but an initial risk assessment identified the East Coast of Sabah as a potential high risk area (within the context of Malaysian exposure) due to it's position relative to active tectonic zones in the Sulu and Celebes Seas. The present paper outlines the study scope and methodology and discusses some of the challenges faced in producing relevant and useful risk mapping on a regional scale.

\section{STUDY OUTLINE}

The main study objective is to produce tsunami risk maps which can be used by planners and authorities to take tsunami risks into account in development planning along the coastline. The risk maps may further be used for prioritising emergency response plans and could be a component of a tsunami

${ }^{1}$ DHI Water \& Environment (Malaysia) Sdn. Bhd., $11^{\text {th }}$ Fl. Wisma Perindustrian, Jalan Istiadat, 88400 Kota Kinabalu, Sabah, Malaysia.

${ }^{2}$ Coastal Section, Federal Department of Irrigation and Drainage. Jalan Sultan Salahuddin. 50626 Kuala Lumpur. Malaysia. 
warning system if this were to be developed. The overall risk is a product of the tsunami generated hazard(s) and the vulnerability. Risk maps are developed through vulnerability and hazard mapping.
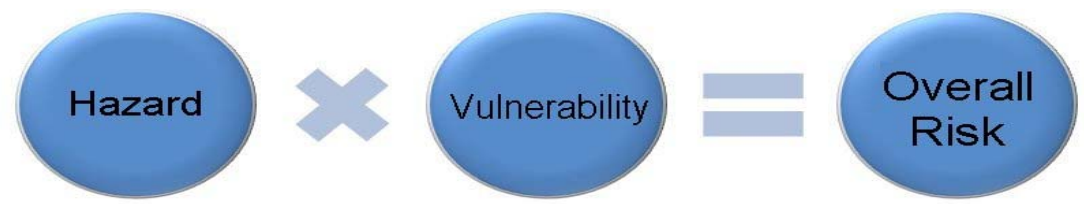

The tsunami hazards are numerous and may include a turbulent bore on beaches, flooding, fast flowing water potentially full of debris, collapsing structures, entrapment in building, etc. Hazard indices can be produced based on inundation depths and current velocities if this can be resolved, or e.g. based on a maximum tsunami wave height along the coastline if overland flow is not resolved. The vulnerability assessment includes development of socio-economic and environmental indices which are weighted together to produce a combined vulnerability map. Population density and escape routes to higher (safe) grounds are critical factors in the vulnerability.

It is noted that the present risk assessment is non-probabilistic, i.e. no attempt is made in trying to ascribe a probability of a tsunami occurring. There are no records known to the authors of tsunamis impacting Sabah, and although there are active subduction zones that potentially could generate a tsunami which could reach Sabah, it is not possible to ascribe a probability to this event. Rather, the areas potentially at risk IF a tsunami is triggered at known subduction zones are identified and mapped in relative terms.

\section{Characterization of Study Area}

The Malaysian state of Sabah is located on the north tip of the island of Borneo. It faces the South China Sea to the west, and the Sulu and Celebes Seas to the north-east and south-east, respectively, see overview on Google Image in Fig. 1.

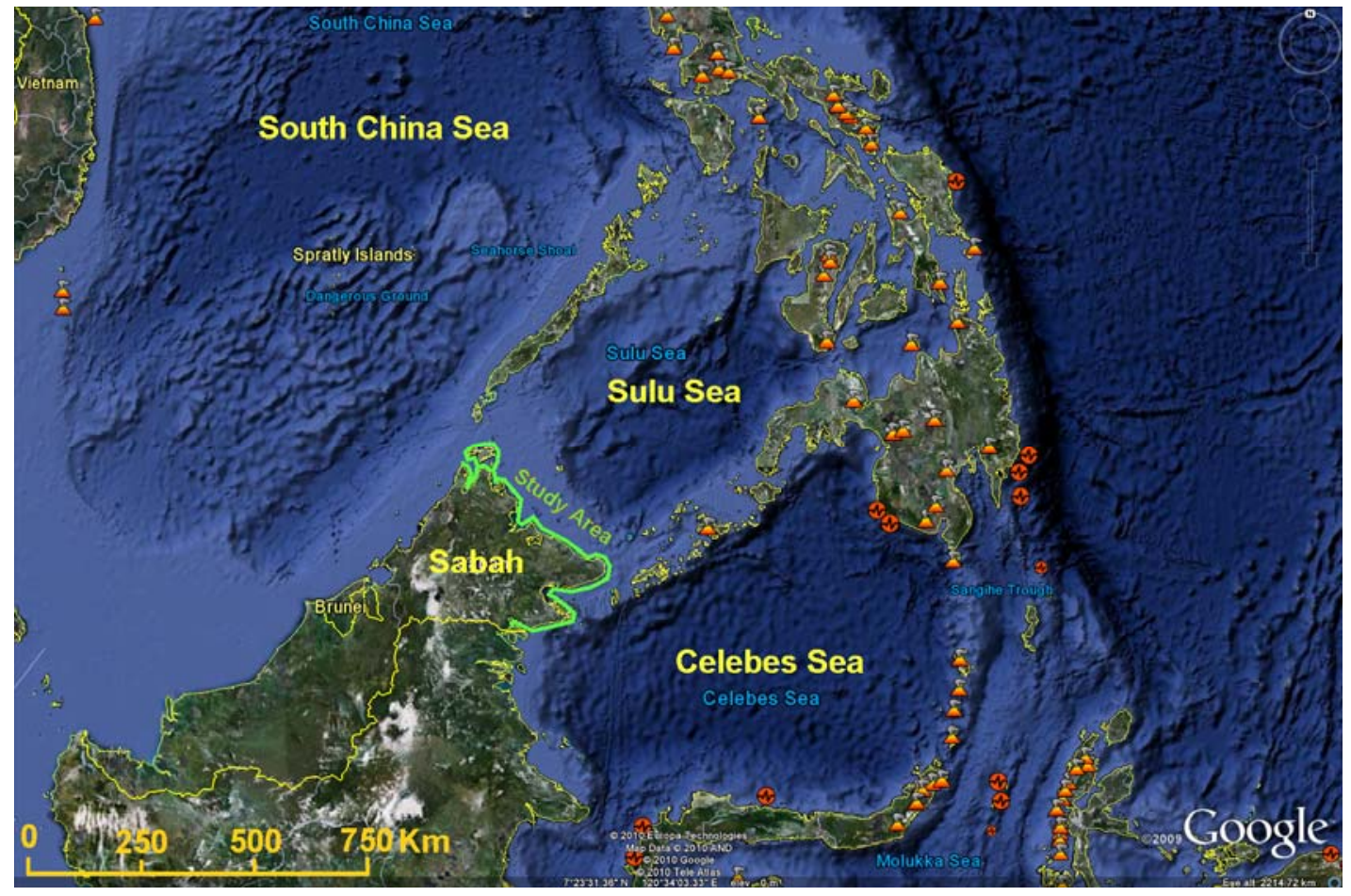

Figure 1. Overview of study area (coastline outlined in light green). Sabah is fronting the Sulu Sea towards the north-east, and the Celebes Sea towards south-east. Source: Google-Earth. 
All three surrounding seas have abyssal plains with depths in the order of $4-5 \mathrm{~km}$. The three seas are separated by Palawan between South China Sea and Sulu Sea, and the Sulu Archipelago between the Sulu Sea and Celebes Sea. Close to Sabah, the Balabac Strait that connects the Sulu and South China Seas is generally shallow with numerous reefs and outcrops, whereas the Sibutu Passage that connects the Sulu and Celebes Seas is relatively deeper and wider, potentially allowing some exposure of the Sulu Sea coastline to tsunamis generated in the Celebes Sea.

The width of the continental shelf around Sabah is generally in the order of $100 \mathrm{~km}$, although it is as narrow as about $10 \mathrm{~km}$ at the south-eastern part of the study area. The shelf area is dominated by relatively shallow water depths of 10-30 m with an abundance of reefs, islands and rocky outcrops, see example on sea chart in Fig. 2. Although exposed to the North-east monsoon generated waves from the Sulu Sea, the coastline is relatively sheltered by the shallow water and the numerous islands and reefs, and mangrove areas are abundant along the sheltered coastline.

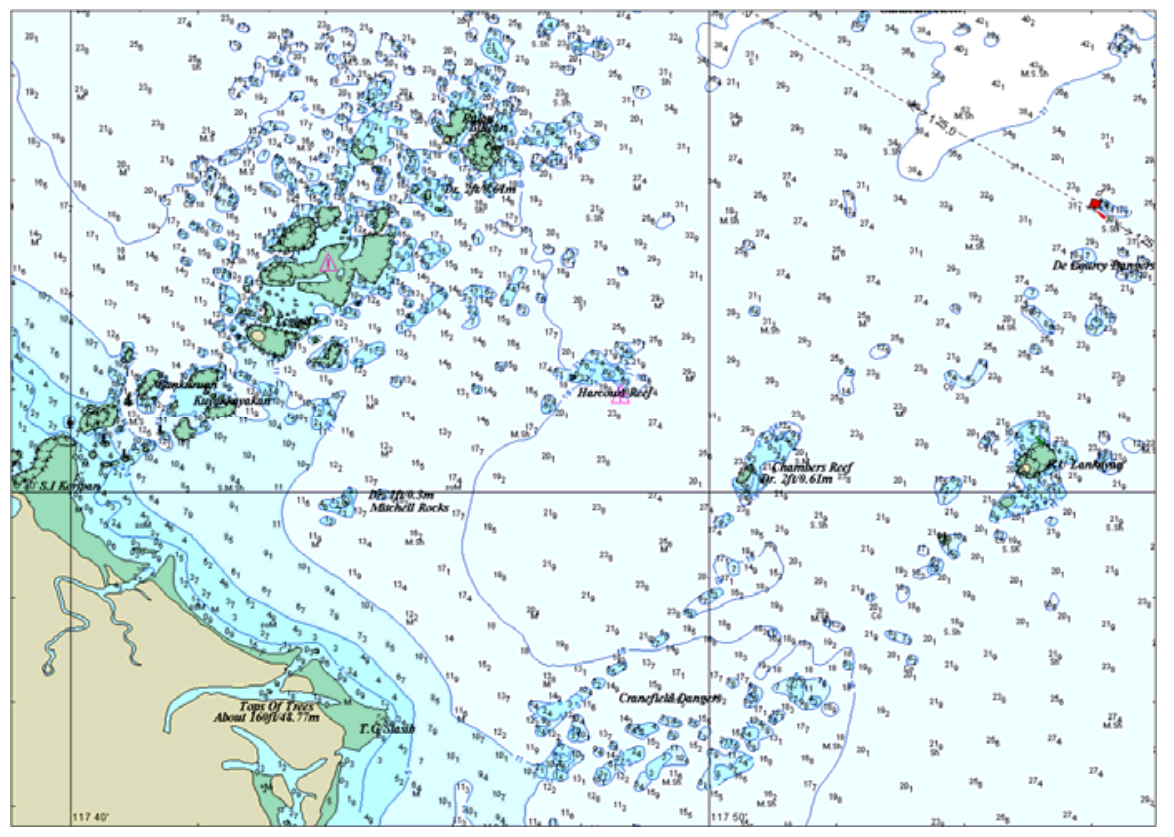

Figure 2. Example of area with reefs and outcrops over the relatively shallow continental shelf surrounding Sabah.

Large proportions of the East Coast of Sabah are sparsely populated with remote fishing villages with limited access and means of communication. The main population centres are located on the coastline, see population density map in Fig. 3. "Water villages", which consist of houses typically constructed on wooden stilts and accessible via boat and narrow walkways, see sample pictures in Fig. 4, are a traditional way of constructing houses and commonly found along Sabah's east coast. They are predominantly found over tidal flats and in shallow waters in relatively sheltered locations where wave exposure is limited by fetch and water depth. Over the past couple of decades, mangroves have been cleared to give way for water villages or other development in many areas. The tidal range is moderate along Sabah's east coast with a difference between MHHW and MLLW in the order of 2 metres. The houses and walkways are adapted to the relatively sheltered conditions and limited tidal ranges, and the freeboards of the floor levels over high tide levels are generally fairly limited. It would therefore not take a very high tsunami wave to cause havoc in a water village. Although mostly restricted to one floor level, population density is high in water villages, and as escape routes generally are via equally low-lying and flimsy walkways, the water villages can be considered dangerous traps if impacted by a tsunami. The widespread presence of water villages and small settlements generally found on or immediately adjacent to the beaches or within mangrove areas along the coastline leads to a relatively high vulnerability to even small or moderate tsunamis. 


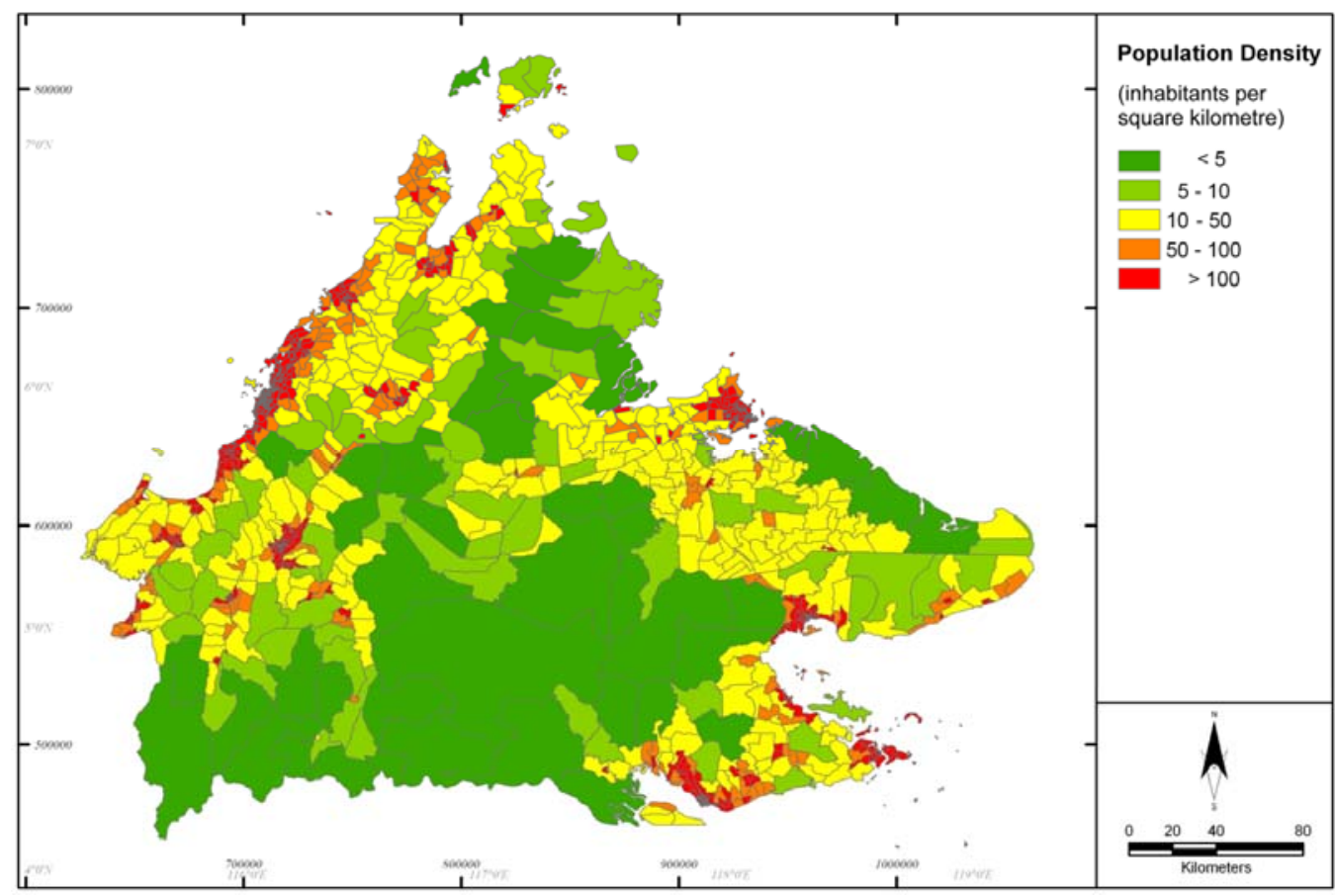

Figure 3. Population density map for Sabah. Large areas of east coast is sparsely populated. Main population centres are along the coastline.

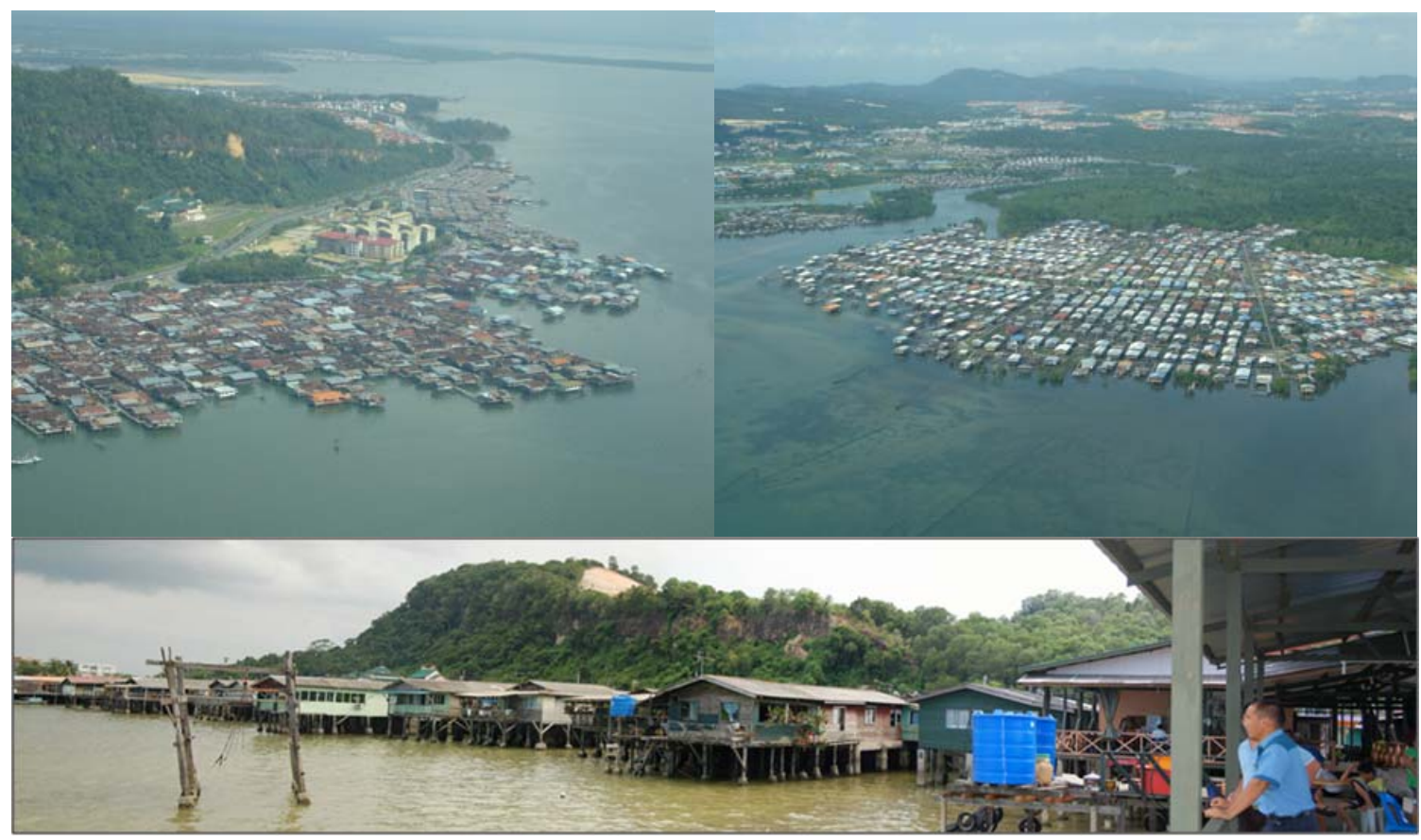

Figure 4. Water villages, consisting of (normally rather flimsy) wooden houses on wooden or concrete stilts are a traditional type of housing commonly found along the coastlines of Sabah, both as small settlements and at the main population centers. 


\section{HAZARD ASSESSMENT}

The hazard mapping is carried out through the aid of numerical modelling by propagating tsunamis from identified potential tsunami sources to the coastline of the study area. This involves the following steps:

1. Identification of potential sources of tsunami. This is primarily related to earthquakes, but could also be landslides (major slides into the sea and/or subsea slides e.g. on the edge of the continental shelf), subsea volcanic eruptions, meteor impacts, etc.

2. "Geological modelling" to quantify initial water displacement and generated waves.

3. Tsunami propagation modelling from source to area of interest using an appropriate hydrodynamic model. This often covers 1000's of kilometers, and important considerations have to be made in relation to model setup, resolution and limitations.

4. Potential detailed overland flow modelling, which may require a separate model, and certainly requires a finer resolution.

From the model results, the chosen hazard indicators can be derived and mapped at appropriate scale. With a coastline of well over $1000 \mathrm{~km}$, the level of detail for the present study is limited.

\section{Source Identification}

Tsunamigenic earthquakes typically happen at subduction zones when the edge of the upper tectonic plate is dragged (or bent) downwards by the lower (subducting) plate, and stresses build up until they are suddenly released by the edge of the upper plate shifting back upwards. The rapid upward shifting of the plate boundary can generate a tsunami. Potential tsunami sources that could impact Sabah have been mapped for the study by a specialist in structural geology, Dr. Felix Tongkul of University Malaysia Sabah. Based on historic records of earthquakes and tsunamis in the waters surrounding Sabah, see Fig. 5, he identified potential tsunamigenic subduction zones and divided these into hypothetical fault segments, see Fig. 6.

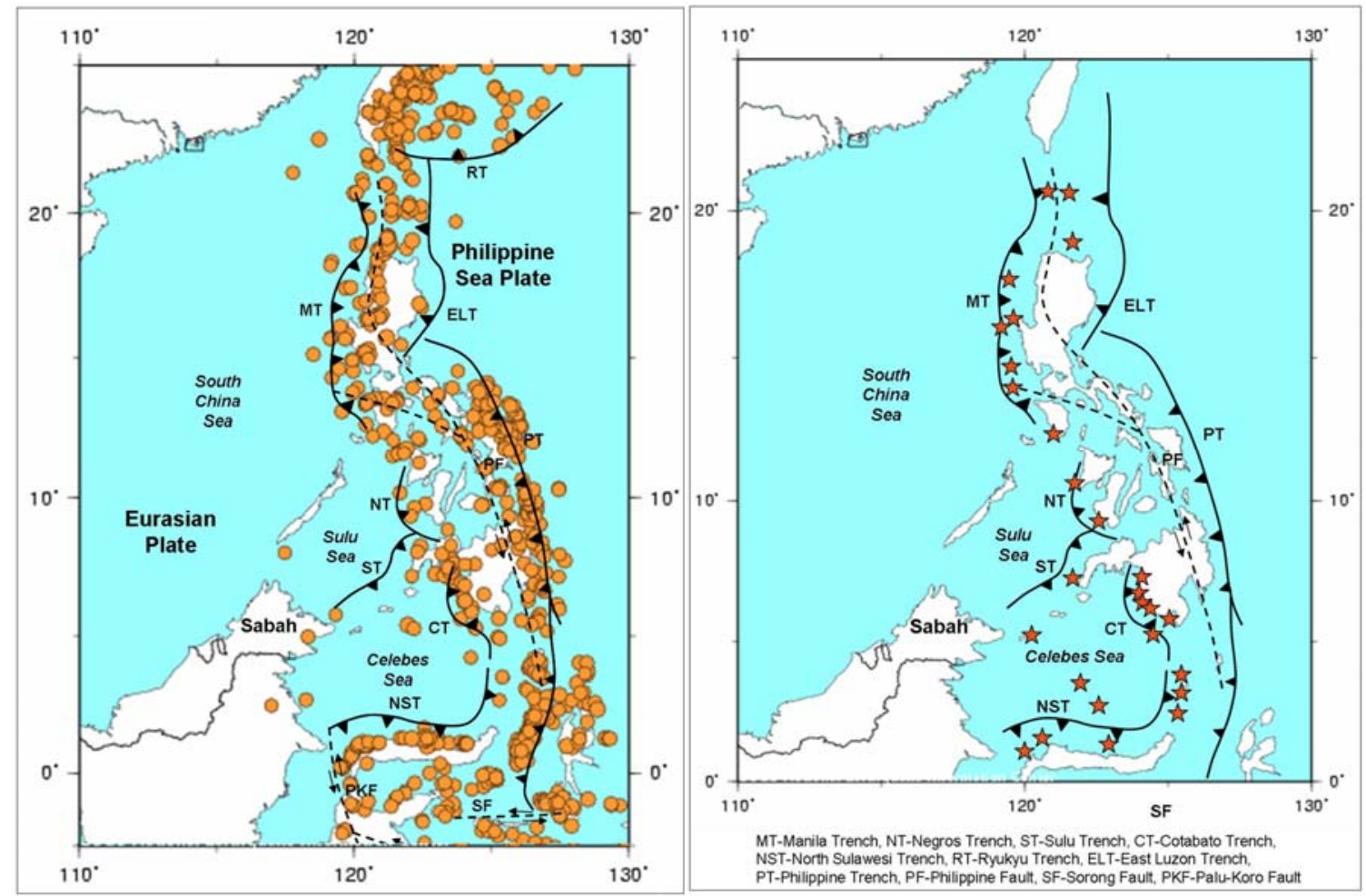

Figure 5. On the left: Epicentres of earthquakes (Mw>5.5) with shallow foci (<33 km) from 1973 till 1999 (Based on USGS/NEIC 2009). On the right: Records of historic tsunamis (Based on NOAA/NGDC 2009). 


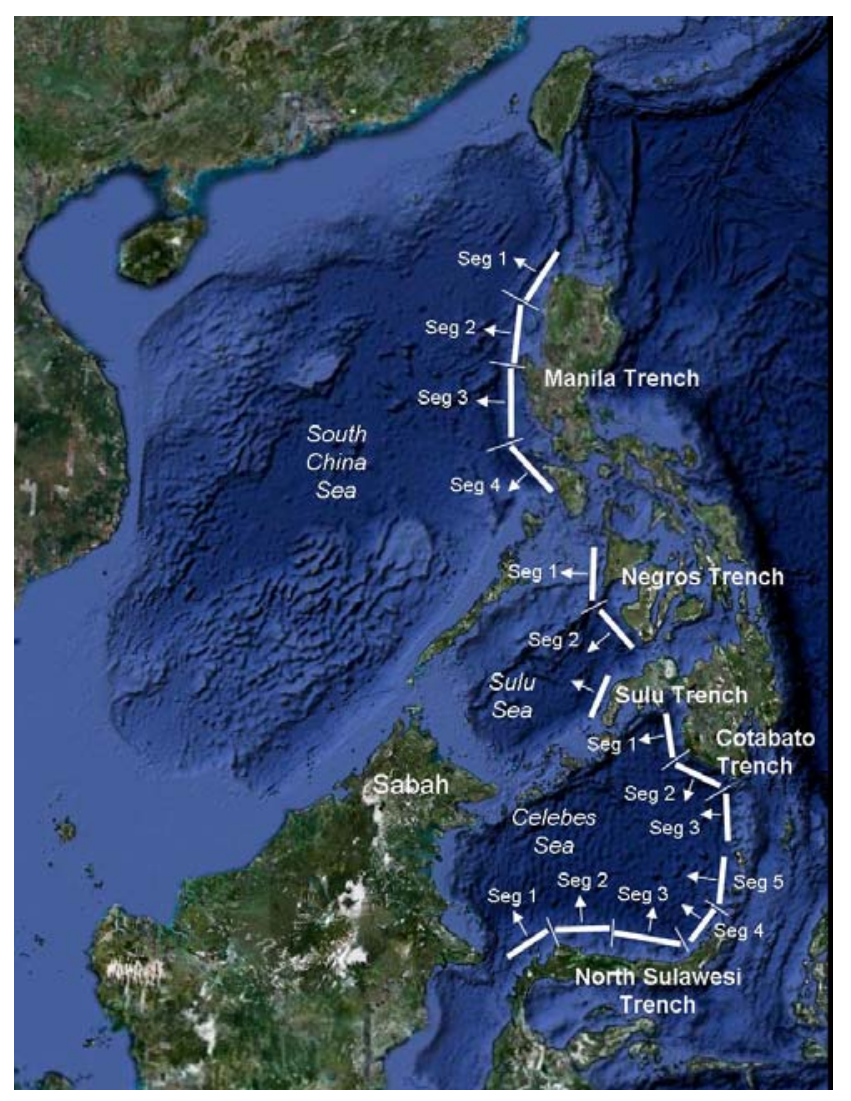

Figure 6. Locations of hypothetical fault segments defined along the main subduction trenches capable of producing tsunamis that could potentially impact Sabah. Source: Dr. Felix Tongkul, University Malaysia Sabah.

For each segment, a set of fault line parameters such as location, slip and dip angles and depth, required for the geological modelling, was defined. A "likely maximum" magnitude earthquake was also defined for each fault segment. This is largely delimited by the length of the fault segment. As

demonstrated by Fig. 5, there are several active subduction zones close to the Philippines that do give rise to tsunamis on a regular basis. Whereas some of these tsunamis have caused significant destruction and loss of life in both the Philippines and Indonesia (Sulawesi), the authors are not aware of records of structural damage or loss of life due to tsunamis in Sabah. This does not necessarily mean that Sabah has not been impacted by tsunami in the past. As previously outlined, there are large stretches of coastline in Sabah which are uninhabited or very sparsely inhabited, and a tsunami in these areas may not be recorded. Minor tsunamis may also not be recognized as such, and therefore not recorded.

\section{Geological Modelling}

Based on the established fault segments and parameters, the in-house QuakeGen tool for "geological modelling” developed by Stefan Leschka, see e.g. Leschka et. al. 2008, was applied to derive the initial sea bottom and water displacement, which in turn is used as starting conditions for the hydrodynamic models, either directly as a time varying bathymetry or as an initial water level displacement. Different methods for calculation of these displacements are available. Implemented in QuakeGen is Okada's (1985) doublecouple method with an extension, derived by Okal (reported in Hesselink, 2008). It is noted that the plate shifting and the resulting initial disturbance can be highly variable for a given zone, and the defined earthquake parameters for each segment and the related geological modelling is obviously highly simplified. The main variables applied for the present regional scale study are the locations and earthquake magnitude. 


\section{Tsunami Propagation Modelling}

A hydrodynamic nested grid modelling complex using Mike21 (DHI 2009) was established to model the tsunami wave from the source to the nearshore area. The tsunami propagation modelling provides information on wave heights along the coastline, which may be used as a hazard indicator. Other output comprises the travel time from the source to a given location, i.e. the "warning/evacuation time" available from the earthquake takes place till the tsunami hits at any given location. An example of regional scale tsunami wave propagation from Negros Trench, Segment 2, see Fig. 6, to the shoreline of Sabah is shown in Fig. 7. The time since the initial earthquake is shown in the upper left corner for each instantaneous plot.
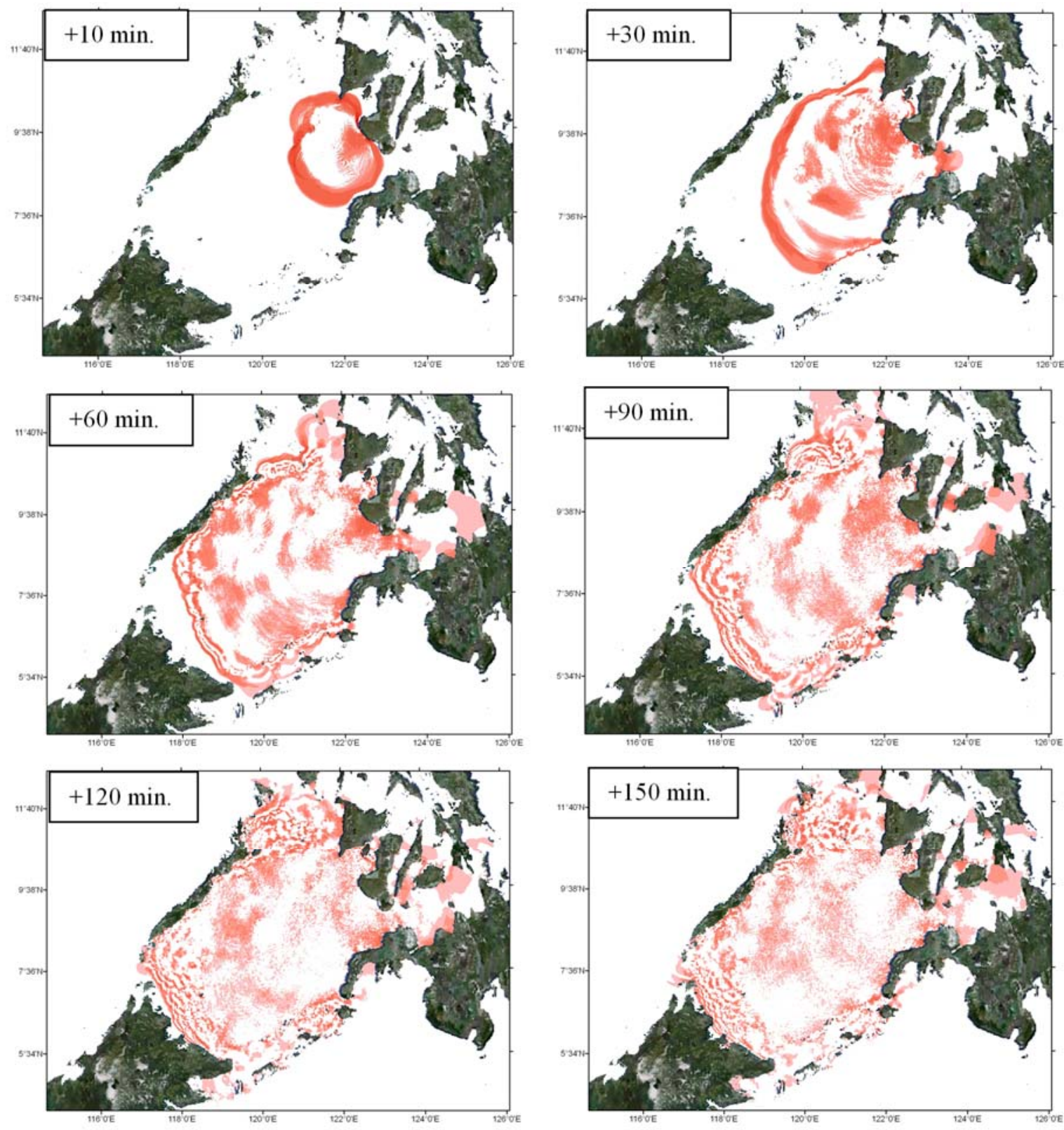

Figure 7. Example of regional tsunami propagation modelling from source in the Sulu Sea (Negros Trench Segment 2, see Fig. 6) to the coastline of Sabah. Only the positive waves are shown. Time since earthquake shown in upper left corner of each figure. 
The tsunami travels rapidly over the deep water basin of the Sulu Sea (speed of propagation is approximately equal to that of a shallow water wave, i.e. proportional to the square root of the water depth). The speed then obviously slows down significantly over the continental shelf, and the wave further starts to loose it's energy and split up. The reduction in travel speed and the arrival times are further illustrated in Fig. 8, which shows the position of the front wave at 20 minute intervals after the earthquake. Similar travel times are illustrated in Fig. 9 for a tsunami generated in the Celebes Sea at Sulawesi North Trench, Segment 5.

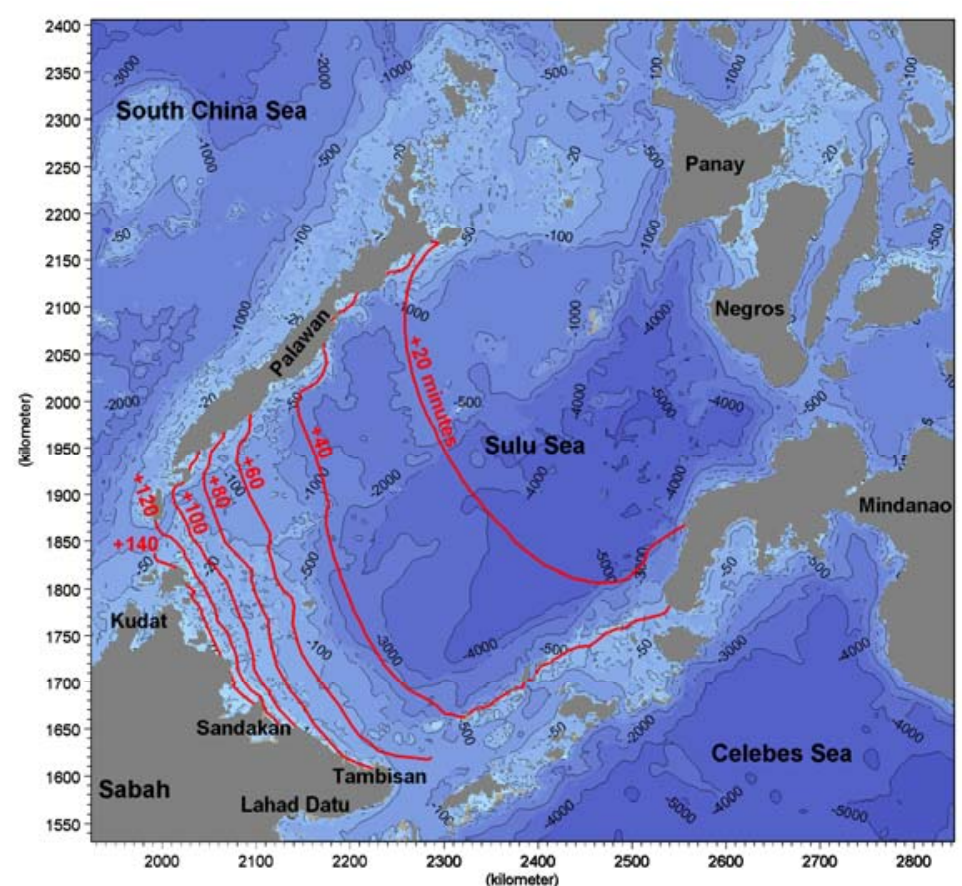

Figure 8. Approximate locations of front wave at $\mathbf{2 0}$ minute intervals based on tsunami generated at Negros Trench, Segment 2.

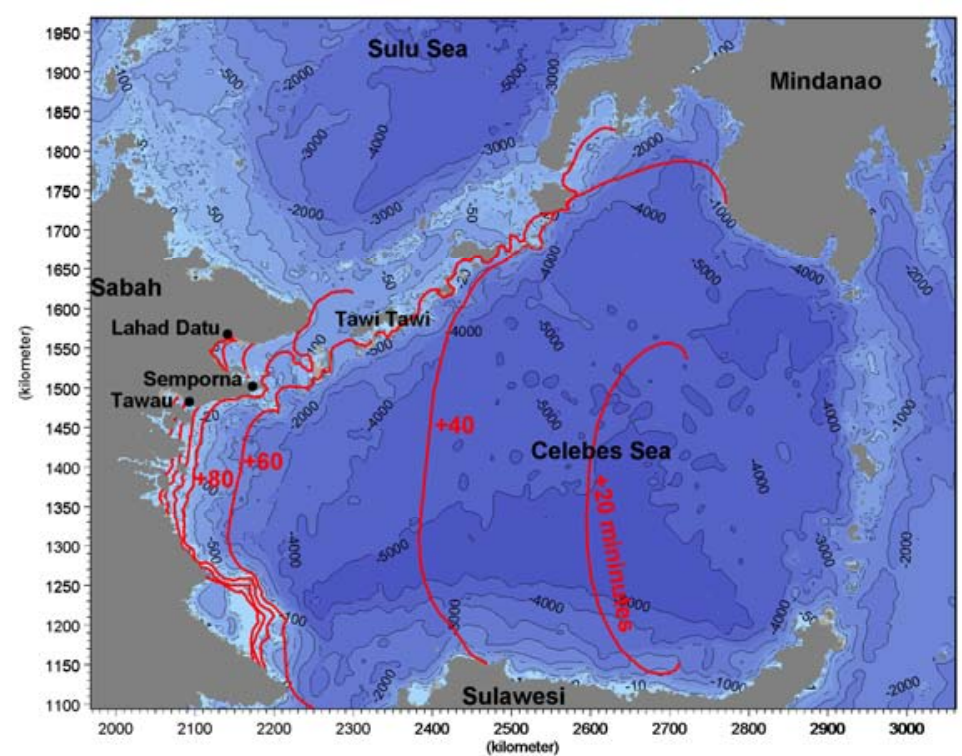

Figure 9. Approximate locations of front wave at $\mathbf{2 0}$ minute intervals based on tsunami generated at North Sulawesi Trench, Segment 5. 
Typical travel times for the first wave to arrive in Sabah from the sources at Visayas and the eastern end of Sulawesi is in the order of 1 to 1.5 hours. Even shorter travel times are possible from sources at the western end of the North Sulawesi Trench. In terms of a potential warning and evacuation system, such short lead time obviously poses a serious challenge.
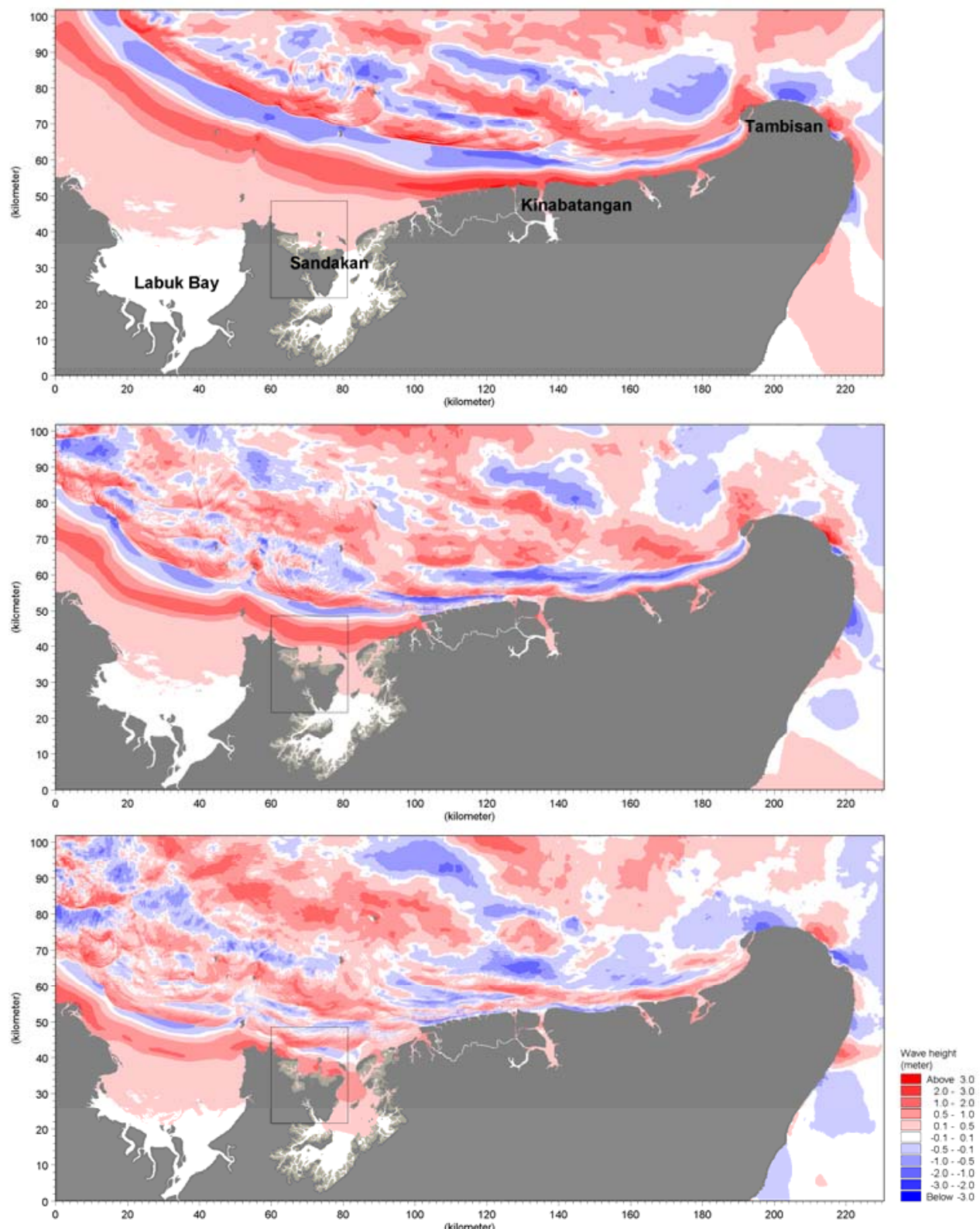

Figure 10. Example of initial wave approach closer to shore of Sabah for tsunami generated at Negros Trench, Segment 2.

Details of the tsunami arrival along part of the east coast of Sabah are illustrated in Fig. 10 with three instantaneous surface elevation plots. It is noted that the study at the time of writing is ongoing, and the shown plots are for demonstration purposes only as the shown elevations are for an unrealistically high magnitude earthquake. The instantaneous plots illustrate a series of waves of which the first is fairly "well structured" along the coastline, while the following waves are much more broken up and variable in direction and magnitude. 
Fig. 11 illustrates maximum wave heights derived in the same area as the instantaneous plots in Fig. 10 on a 90m grid resolution. The maximum wave heights are derived from output at 2 minutes intervals, which leads to the striped appearance of the plot. The maximum wave height plot illustrates significant variations along the coastline, which is due to the uneven dissipation of energy, refraction and diffraction around islands and reefs, resulting in dispersion and concentration of energy along different sections of the coastline. This emphasizes the need for good definition and resolution of the bathymetry over the continental shelf. Sensitivity testing has been carried out and is briefly outlined in the following section.

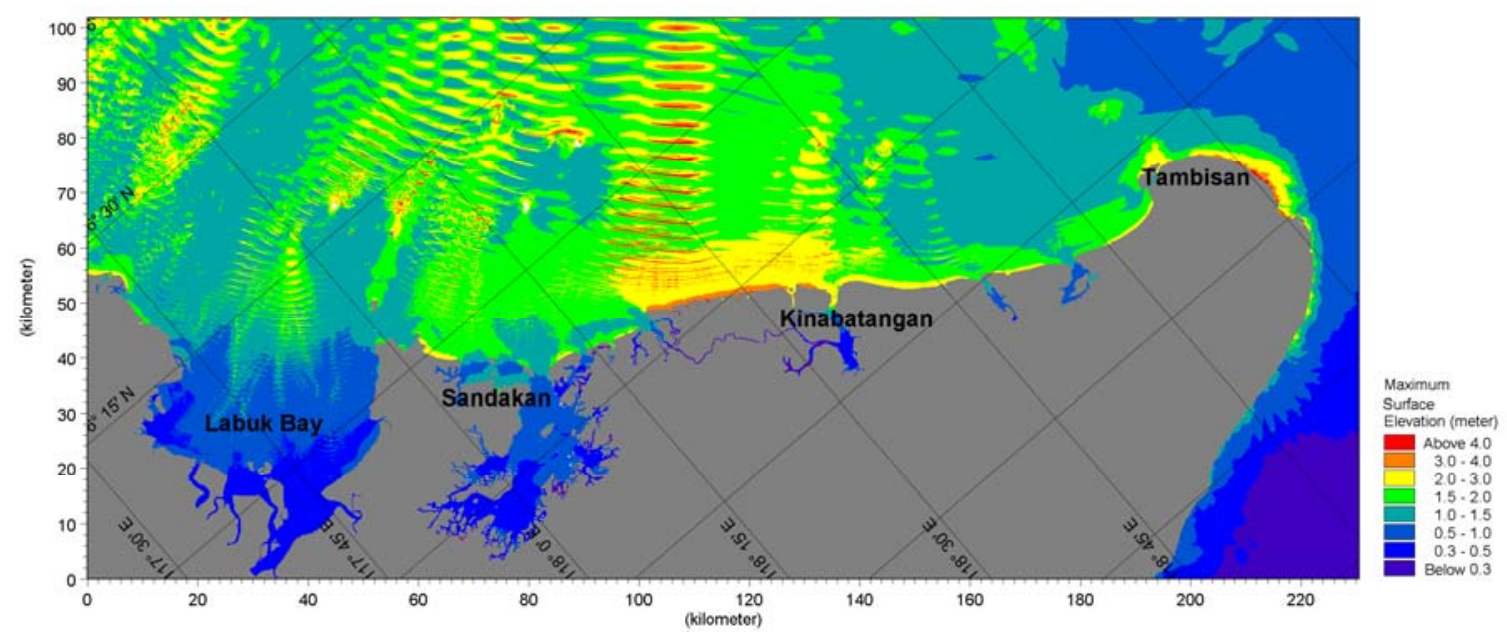

Figure 11. Variations in maximum wave height along a stretch of shoreline from the eastern tip of Sabah . Negros Trench, Segment 2.

\section{MODELLING CHALLENGES}

\section{Bathymetry Resolution}

As outlined in the site description, the nearshore bathymetry over the continental shelf is complex with islands, reefs and outcrops. This area is critical in slowing the tsunami propagation and dissipating part of the energy to reduce the impacts on the coastline of Sabah. This is for instance seen in Fig. 7 and Fig. 8 with the Negros Trench generated tsunami reaching the northern tip of Sabah more than an hour later than it reaches the eastern tip at Tambisan, despite the distance from the source being fairly similar. This is due to a wider and shallower continental shelf towards the northern tip of Borneo compared to the eastern tip. There are large variations in the maximum generated tsunami wave heights along the coastline as illustrated in Fig. 11. The very non-uniform distribution of maximum wave height along the coastline is caused primarily by the variable bathymetry in shallow water leading to differential energy dissipation along the coast as well as refraction/diffraction of the waves and related concentration of energy in some areas.

From a risk assessment point of view, it is important to understand the reliability of the modelled hazard indicators such as the maximum tsunami wave height along the coastline. The uncertainties can be divided into two main categories:

1. Uncertainties related to the source.

2. Uncertainties related to the modeled propagation of the waves from the source to the site.

The first category is geologically dependent and uncertainty is obviously high, both in terms of the source strength and distribution. For a non-probabilistic, regional scale study like the present, where the main objective is to identify areas potentially at risk, this uncertainty is dealt with by adopting a range of relatively conservative maximum strength earthquakes for the generation of the initial sources. The second category uncertainty related to the modelling of the tsunami propagation, sensitivity testing to a number of parameters is being carried out. An example of testing for data scarcity and model resolution is included below. 
The main source for bathymetry information has been electronic nautical charts at varying resolution throughout the area. On the nautical charts, coral reefs are generally represented by a single or few high points surrounded by shallow contour(s). The deeper channels between the reefs and the open water areas are generally only represented by scattered points. Whereas the reef walls are usually steep in nature, direct interpolation in the bathymetry information extracted from electronic nautical charts normally leads to shallow side slopes and/or shallow, broken channels between the reefs. Significant work is required to refine the model bathymetries to obtain a good representation of the coral reefs. Examples of model grids in 10 and $30 \mathrm{~m}$ resolution interpolated directly from the data derived from nautical charts and from a data base with additional contours added to resolve the reef slopes and deeper channels are shown in Fig. 12. A significant reduction in the shallow areas is introduced with a better resolution of the reef slopes in the data set.
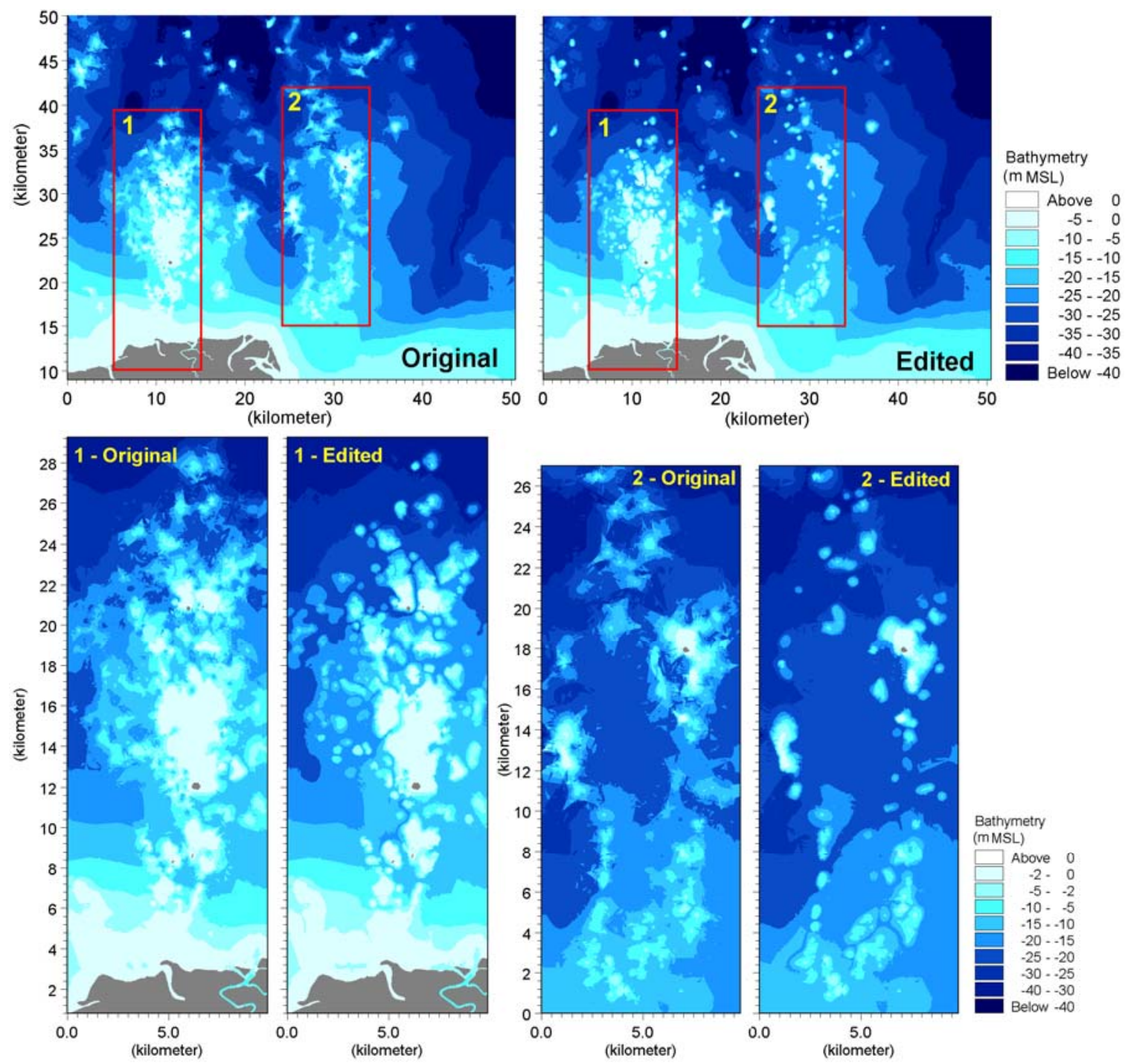

Figure 12. Example of bathymetries derived from Sea Charts over the continental shelf area on Sabah's northeast coast. Top: Comparison of $30 \mathrm{~m}$ grid resolution directly interpolated from data derived from nautical charts (left) and interpolated from data set with additional contours to better define reef slopes and deeper channels. Bottom figures compare the two reef areas outlined in the top figure in $10 \mathrm{~m}$ grid resolution.

Maximum wave height along the coastline derived from the two sets of bathymetry, i.e. directly interpolated from the data base derived from nautical charts and the extended data base to improve the reef 
slopes, are compared in Fig. 13 for a model resolution of nested 10 and 30m grids in the nearshore reef areas per Fig. 12. Whereas there are differences in the modelled maximum wave heights, these differences are considered of limited magnitude relative to for instance the uncertainties related to the tsunami source term for the present example. In cases with more coherent reef structures, the differences may be larger and the reef resolution of greater importance.
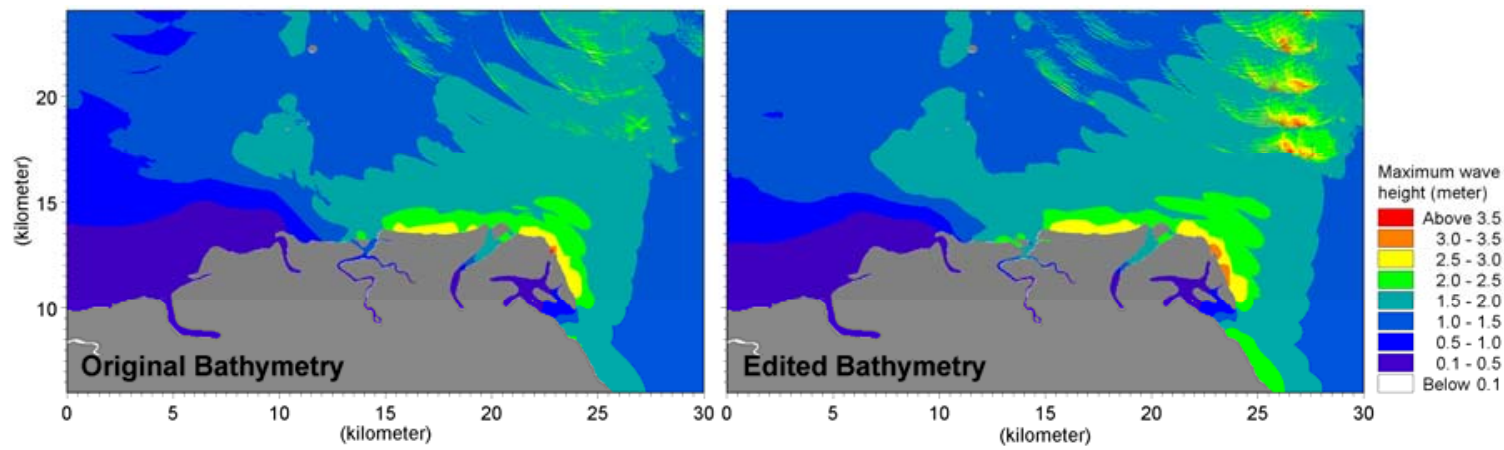

Figure 13. Maximum wave heights along coastline using nested 30 and $10 \mathrm{~m}$ grids based on original and edited bathymetry data base, respectively, per Fig. 12.

\section{Model Grid Resolution}

The influence of grid resolution has also been tested. Fig. 14 shows the same comparison as Fig. 13 but excluding the 30 and $10 \mathrm{~m}$ grid resolution, such that the entire area is covered by a $90 \mathrm{~m}$ grid resolution. Comparing Fig. 14 to Fig. 13, the patterns are fairly similar, and it can be concluded that for estimation of maximum wave heights along the coastline on a regional scale, the $90 \mathrm{~m}$ grid resolution seems to be sufficient at the present site. In areas with narrow channels which need to be resolved, this may not be the case.
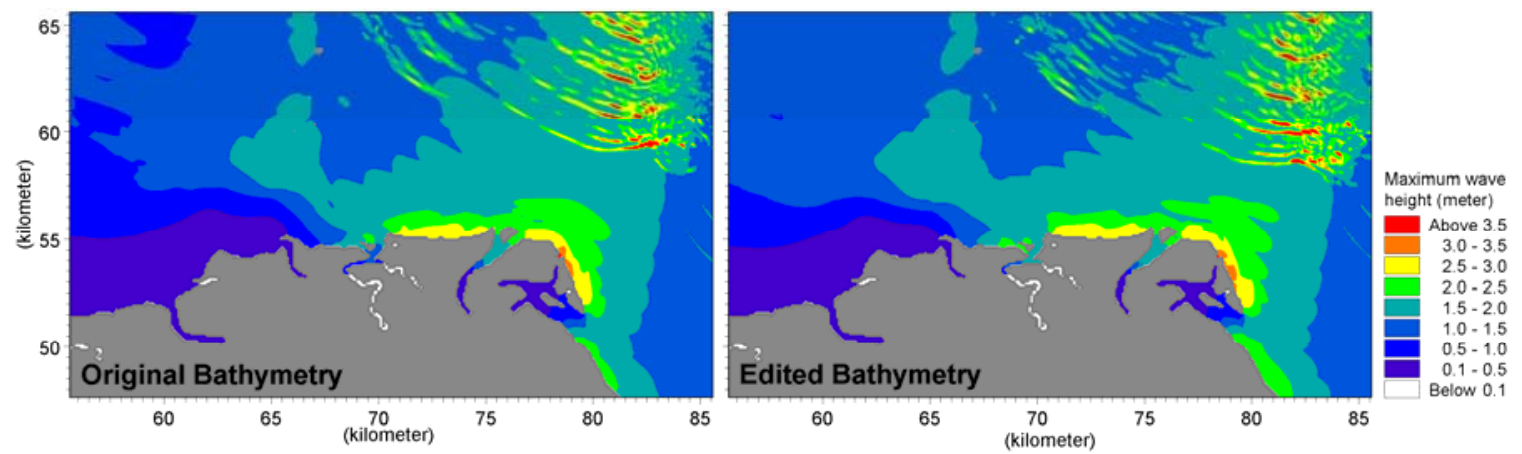

Figure 14. Maximum wave heights along coastline using nested $90 \mathrm{~m}$ grids based on original and edited bathymetry data base, respectively, per Fig. 12.

\section{Overland Flow Modelling}

The objectives of overland flow modelling for tsunamis would typically be to obtain information on e.g. flow pathways and extent of inundation for detailed risk mapping and e.g. planning of safe zones and evacuation routes. Before embarking on overland flow modelling, it should be recognized that this adds a level of complexity to the modelling on several fronts:

1. The tsunami may change character to a broken bore, and resolving the flow patterns may require a Boussinesq type model.

2. Very fine resolution is required if the full flow details are to be resolved in complex areas (such as built-up areas).

3. High accuracy and resolution topographic data is required.

4. The surfaces are generally highly variable, leading to vastly different flow resistance and energy dissipation within a typical model domain.

5. The presence and build-up of debris may change the flow patterns. 
For the tsunami study for the east coast of Sabah, limited overland flow modelling has been carried out in isolated high-risk areas, typically densely populated, low lying areas at risk of significant tsunami impact. A key issue has revolved around the topographic data, which is a critical component for reliable overland flow modelling. High resolution LIDAR (Light Detection and Ranging) data was beyond the budget and timeframe of the study, and the cheaper but also less accurate IFSAR (Interferometric Synthetic Aperture Radar) data has been tested. A Digital Surface Model (DSM), and a Digital Elevation Model (DEM) is provided. The DSM maps the surface of highest points, i.e. inclusive of buildings, (dense) vegetation, etc. while the DEM intends to map the elevation of the earths surface excluding vegetation, houses, etc. (i.e. "ground" level). For overland flow modelling, the choice between the two is not necessarily straight forward. "Permeable" features such as trees and other vegetation is generally included in the model based on the DEM combined with an increased flow resistance. Stable "impermeable" building, i.e. buildings which will maintain their integrity through the tsunami and which the water will flow around, can be included as a feature in the bathymetry for a very fine resolution model with the intention of resolving the flow on street level, or they can be represented by an increased flow resistance for built-up areas in a coarser grid model. Houses on stilts (see Fig. 4) obviously allow water to flow under them with limited additional resistance, but for a higher wave where the water level exceeds the floor level, the flow resistance will increase significantly. Even with good DSM/DEM available, producing a high resolution bathymetry for overland flow modelling generally requires a great deal of effort to achieve good results.

For the present study, which had to cover fairly extensive areas for the overland flow modelling to provide any value in terms of the risk mapping exercise, a fine grid $(10 * 10 \mathrm{~m})$ extension of the general hydrodynamic module (Mike21 HD) was tested. A resistance map was included based on the values recommended by Leschka 2009, and the bathymetry developed based on the IFSAR DEM.
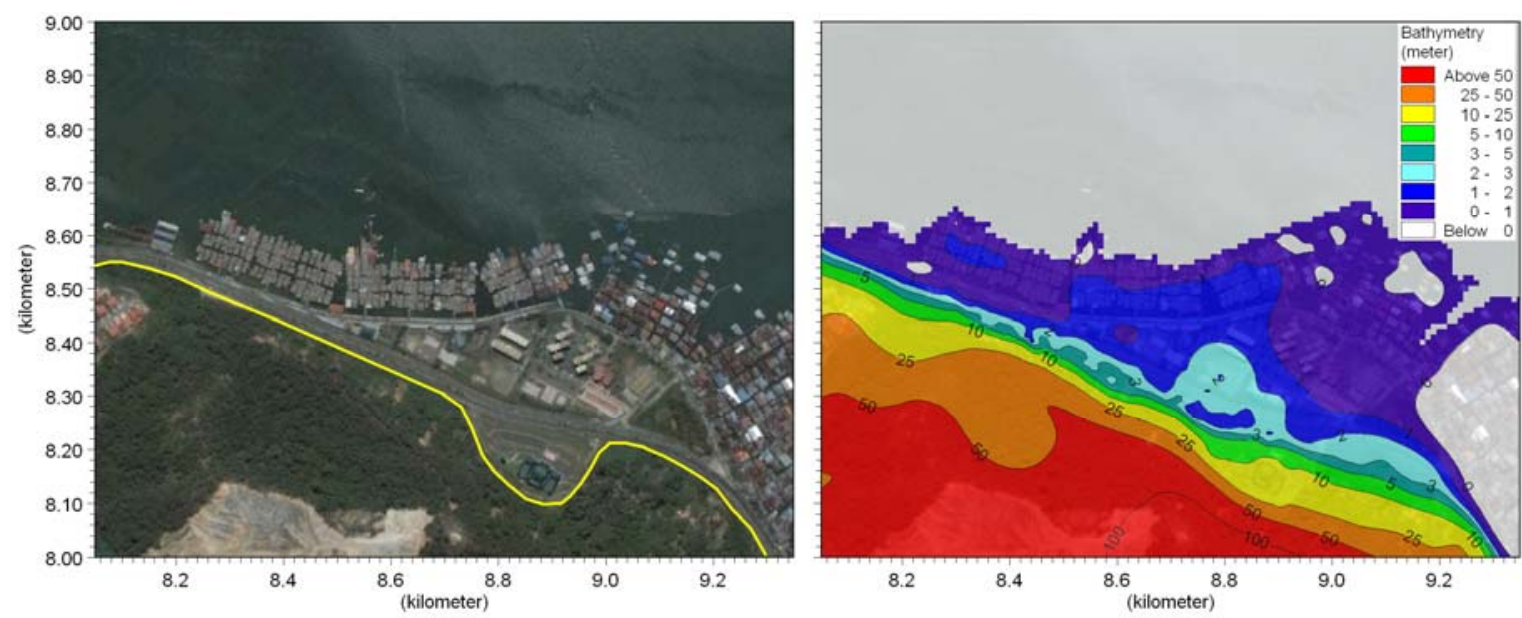

Figure 15. Sample area at Sandakan with steep cliff face (below yellow line on Google Image on the left) fronted by coastal road and water village (houses on stilts) over shallow area along the coastline. Right-hand image illustrates bathymetry interpolated from IFSAR DEM directly.

Fig. 15 illustrates a section of model bathymetry interpolated from the IFSAR DEM only, i.e. excluding bathymetry data. It is well-known that the vertical accuracy of IFSAR drops significantly on steep slopes, and it is thus not surprising that the steep cliff face is relatively poorly resolved. More worrying, the rise along the seawall around mean sea level seaward of the wall to above $1 \mathrm{~m}$ above MSL landward of the seawall is not well resolved. Fig. 16 shows maximum wave height (over water) and maximum inundation levels (over land) for a tsunami originating at the Negros Trench, Segment 2, see e.g. Fig. 6 and Fig. 11. The maximum wave height is limited at just over 1.5m at this section of coastline. With the simulation carried out at high tide, the tsunami causes some flooding along the coastal strip according to the simulation based on the IFSAR data. The inundation levels higher than $2.5 \mathrm{~m}$ for a tsunami wave height in the order of $1.5 \mathrm{~m}$ in very shallow water along the coastline is clearly exaggerated. This is due to the above mentioned underestimate of the ground level along the coastal strip. 


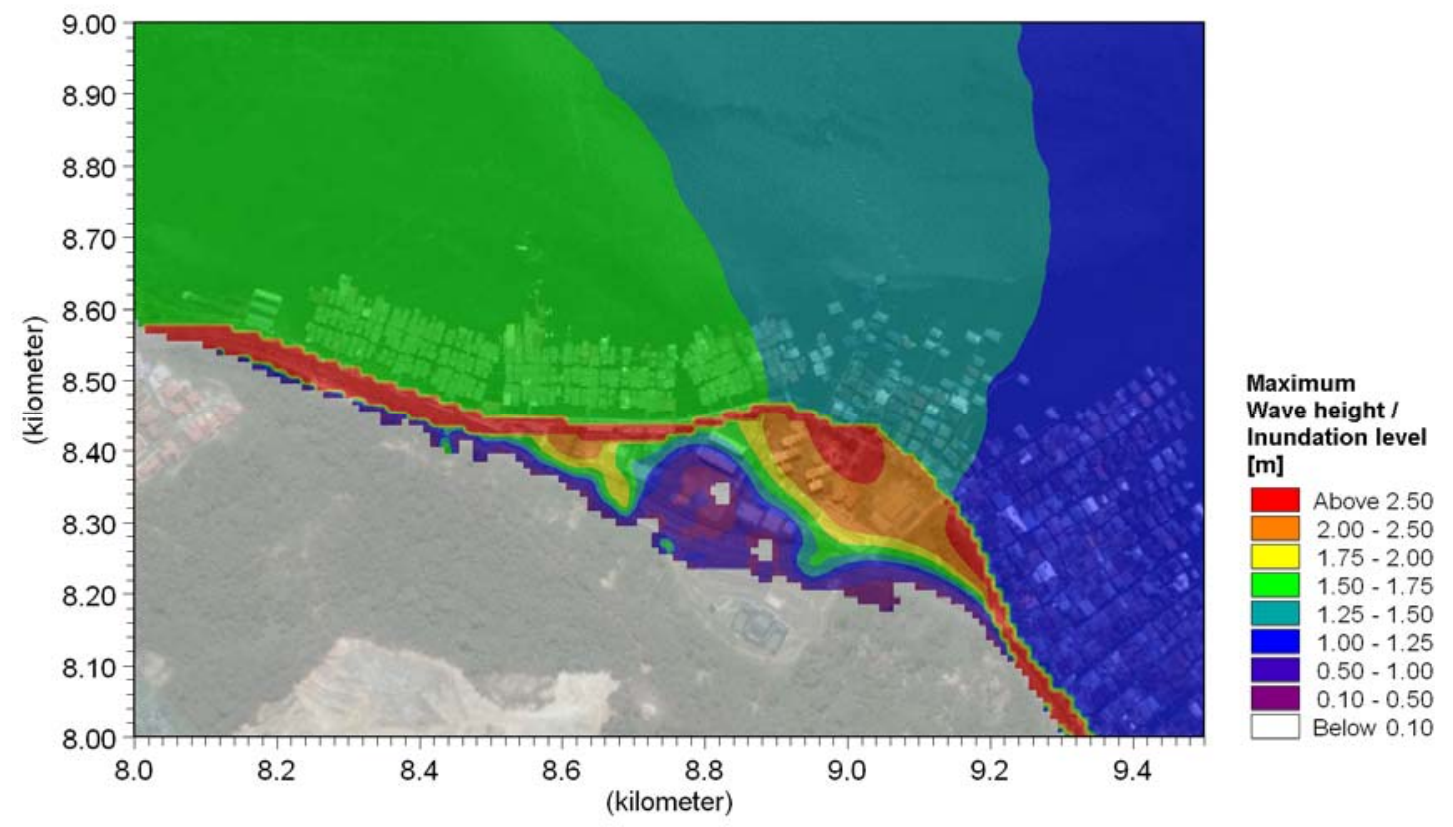

Figure 16. Simulated maximum wave height (over still water level in the sea) and maximum inundation level (over land) for the area in Sandakan shown in Fig. 15.

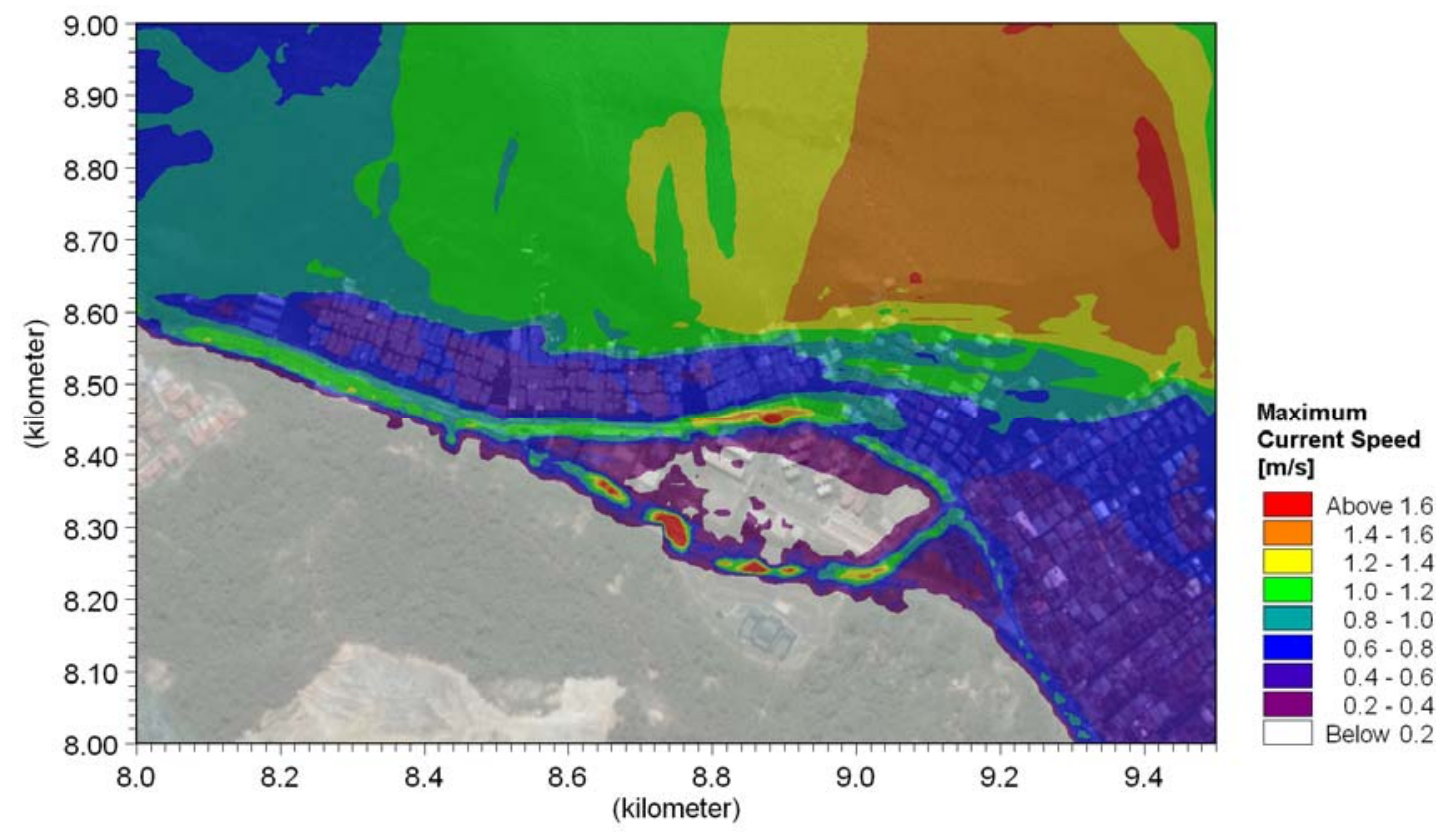

Figure 17. Simulated maximum current speed for the area in Sandakan shown in Fig. 15.

The maximum current plot in Fig. 17 generally shows relatively low values, which is due to the shallow water depths combined with the high resistance for overland flow. The resistance is low along the roads, which shows up in the map as two lines of higher speeds. A relatively high resistance has been applied for the water village for the shown case, which is clearly leading to too high a reduction in current speed in this area. A simulation without increased resistance for the water village shows max current speeds similar to the area seaward of the water village in Fig. 16. In some places, the DEM developed from the IFSAR data tends to have too high elevations if the algorithm to develop the DEM from the DSM is not 
capable of removing all surface objects. This will lead to an under estimation of the tsunami inundation levels and current speeds, and thereby a non-conservative estimation of the tsunami hazard and risk. The value of overland flow modelling may be questioned if the data is not sufficiently accurate. In the present case, the inaccuracies in the topographic data has been found to be of similar same magnitude as the tsunami wave height along the coastline, and it may be better to use the wave height along the coastline as a hazard indicator. This will not provide the areal extent of hazards over land, but may be better than providing inaccurate results due to lack of detailed and accurate data. Attempting to produce detailed risk maps in built-up areas based on inaccurate data may lead to either a false sense of safety or unnecessary alarm.

\section{CONCLUSIONS}

In an area where there are no (known to the authors) registered cases of tsunami impacts, and where there are significant proportions of the population living in relative poverty as traditional fishermen settled on the waters edge, it is a challenge to get tsunami preparedness and planning onto the agenda and taken seriously. The Government of Malaysia is carrying out a risk mapping exercise, which will facilitate the tsunami risk to be considered in future coastal planning. The various steps in the hazard mapping, aided by computer modelling, have been outlined. Although the modelled tsunami wave heights along the coastline for realistic tsunami sources are generally small to moderate, the risks cannot be considered negligible due to the traditional building style with water villages and high population density along the coastline, which leads to a high degree of vulnerability.

Sensitivity testing has shown some influence on the tsunami dissipation by coral reefs and outcrops on the continental shelf, which would require careful consideration for a detailed model exercise, but the details are perhaps less important for a regional scale study. On a regional scale, a grid resolution in the order of $100 \mathrm{~m}$ of the continental shelf area provided similar results as a $10 \mathrm{~m}$ grid resolution. For overland flow modelling, the topographic data base and grid resolution is crucial. Whereas IFSAR data provides a relatively fast and inexpensive source for topographic data, the inaccuracies have for the present case been found to be of similar magnitude to the expected inundation levels, and extreme caution therefore has to be exercised in deriving hazard levels from overland flow modelling based on a DEM derived only from IFSAR data.

\section{REFERENCES}

DHI, 2009. MIKE 21 \& MIKE 3 Flow Model Hydrodynamic and Transport Module Scientific Documentation.

Hesselink, S 2008. Applikationsgestützte Erstellung zeitabhängiger Bathymetrien für die EchtzeitSimulation von Tsunamis aus Erdbeben. Diplomarbeit, Faculty of Civil Engineering and Geoinformatics, University of Applied Sciences Oldenburg, Germany.

Leschka, S., Hesseling, S., Kongko, W. and Larsen, O. 2008. A tsunami generation tool for dynamic sea bottom deformation and its application to the 17 July 2006 Java Earthquake tsunami, E-Proc. of the International Conference on Tsunami Warning (ICTW), DMS18DE, 12-14 November 2008, Nusa Dua/Indonesia.

Leschka, S., Pedersen, C., and Larsen, O. 2009. On the requirements for data and methods in tsunami inundation modelling - roughness map and uncertainties, Proceedings. of the South China Sea Tsunami Tsunami Workshop 3 (SCSTW3), University Sains Malaysia, Penang, 3-5 November 2009.

NGDC (National Geophysical Data Center) 2009. World-wide tsunamis, 2000 BC to 2009. NOAA.

Okada, Y. 1985. Surface deformation due to shear and sensile faults in a halfspace. Bulletin of the Seismological Society of America, 74(4), 1135-1154.

Rastogi B.K. and R.K. Jaiswal. 2006. A catalog of tsunamis in the Indian Ocean. Science of Tsunami Hazards, Vol. 25, No. 3. $128-143$.

Tongkul, F. 2009. Tsunami modeling impact studies for north and east coast of Sabah, Malaysia. Internal study report submitted by Dr. Felix Tongkul, Universiti Malaysia Sabah, November 2009.

USGS/NEIC (United States Geological Survey / National Earthquake Information Centre), 2009. Earthquake database. 